\title{
PEREGRINANDO POR LOS SANTUARIOS DE LA PENÍNSULA DE YUCATÁN
}

\author{
MarTHa Medina Un \\ y TERESA QuiÑones VeGA \\ Instituto Nacional de Antropología e Historia, Centro Yucatán
}

\section{Introducción}

En comparación con otros aspectos de la religiosidad popular, en la antropología mexicana aún queda mucho por estudiar sobre la temática peregrinación-santuario, sobre todo si consideramos que en el territorio nacional hay un sinnúmero de santuarios o lugares sagrados que son centros de peregrinaciones. Tanto en la peregrinación como en el santuario se construyen y fortalecen identidades sociales y se crea cultura.

El objetivo de este artículo es repasar algunas de las contribuciones teóricas y etnográficas al estudio del binomio peregrinación-santuario, así como revisar las aportaciones más recientes sobre este tema en la península de Yucatán. El texto consta de tres partes, en la primera se señalan algunos planteamientos teóricos sobre la temática, luego se tratan algunos trabajos etnográficos desarrollados en México y finalmente se abordan los realizados en la península de Yucatán.

\section{Aproximaciones teóricas a la temática peregrinación-santuario}

Las peregrinaciones a los santuarios son manifestaciones de carácter religioso que las sociedades de la mayor parte de las culturas del mundo realizan alguna vez en su vida. Existen investigaciones dedicadas al estudio de este fenómeno que, como afirman Victor y Edith Turner (1978), son probablemente muy antiguas, dotadas de una estructura institucional, y que existían ya entre los pueblos que los antropólogos llamaban tribales, pero que alcanzaron importancia hasta que formaron parte de religiones como el induismo, el budismo, el judaísmo, el islam y el cristianismo.

Los Turner elaboraron una clasificación de las peregrinaciones sobre una base histórica: la primera es la prototípica, establecida por el fundador de una religión histórica o por sus primeros discípulos, aunque a veces se instauraran en antiguos sitios de peregrinación. Un ejemplo son las realizadas a Jerusalén y Roma por los cristianos, y a la Meca por los islámicos. La segunda es la arcaica, 
derivada de la forma anterior, la cual se caracteriza por su sincretismo. Ejemplo de este tipo es la peregrinación que se efectúa al santuario del Santo Señor de Chalma en México. La tercera fue denominada medieval y corresponde al período histórico comprendido entre 500-1400 de nuestra era. Un modelo de este tipo de peregrinación es la de Santiago de Compostela en España, y el cuarto y último tipo de peregrinación sería la moderna, que se desarrolló durante los siglos xix y xx (Turner y Turner, op. cit.: 17-18).

En el análisis de las peregrinaciones, Turner introduce un concepto, el de la liminalidad, que surge de la propuesta de Arnold van Gennep para el estudio de los ritos de paso en las tribus africanas, y que contempla tres fases; separación, margen o limen y agregación. En las peregrinaciones cristianas se desarrolla un estado similar a la marginalidad o liminalidad que se da en los ritos de paso, consistente en entrar en una fase de transición o una nueva dimensión social. Esta situación se manifiesta evidentemente cuando los peregrinos realizan el viaje al santuario, pues "no están en un sitio ni en otro; no se les puede situar en las posiciones asignadas y dispuestas por la ley, la costumbre, las convenciones y el ceremonial" (Turner, 1988: 102). De esta manera se introducen dos conceptos nuevos: communitas y antiestructura. Comunidad o communitas (preferentemente en opinión de Turner la voz latina) expresa mejor la forma como se conducen los grupos y los individuos durante la fase liminal. En la communitas no existe una estructura, o es de carácter muy elemental, y como consecuencia no se registran jerarquías; todos los miembros del grupo son iguales, y la única autoridad reconocida es la más rudimentaria o simple. Por consiguiente, todos conviven en comunión. La antiestructura, por su parte, es la característica principal de la communitas, dado que significa ausencia de jerarquía y de niveles de autoridad típicos de los grupos sociales.

A partir del estudio de los santuarios marianos de Cataluña, Prat i Carós (1989) plantea lo que llamó una aproximación etnográfica a los santuarios. Propone que el binomio peregrinación-santuario debe de ser abordado en forma general, y no fragmentar su estudio en temas y subtemas (las romerías, los exvotos, las novenas, los mitos de origen y otros subtemas) que se derivan de la devoción religiosa. Sugiere reflexionar sobre el santuario como unidad de análisis y como el marco general de donde se derivan todos los fenómenos que se vinculan unos con otros, de allí la pertinencia de abordarlos en forma global sin perder de vista la importancia y el valor que tienen los aspectos sociales, políticos y simbólicos. Y tampoco dejar fuera del análisis otros aspectos de relevantes como son los eventos históricos y las condiciones ecológicas del santuario (op. cit.: 215).

Por su parte, Diez Taboada (1989) presenta un esquema teórico que pretende ser el ensayo de una teoría del santuario. Con base en los puntos centrales de William Christian, señala que "un santuario es un lugar donde hay una imagen o reliquia que recibe una devoción particular. Un santuario se define por la devoción de la gente y no por una característica histórica o artística inherente a 
un edificio o institución..." (op. cit.: 274). En este sentido debe reunir dos características, ser un espacio dotado por la naturaleza de "una especial capacidad de evocación y vivencia religiosa", y el hecho de que en sitio específico ocurriera una hierofanía o teofanía que, convertida del conocimiento público por los testigos, da lugar a la construcción de un santuario (op. cit.: 274 y 279).

Sobre los orígenes de los santuarios, señala las coincidencias y divergencias entre religiones en diferentes momentos históricos, y la existencia de lugares sagrados cristianos en antiguos templos o santuarios paganos, o el hecho de que algunas edificaciones católicas como ermitas o capillas se construyeran sobre ciertos vestigios arqueológicos prerromanos. Destaca la importancia que pueden tener para algunos pueblos las cuevas y cavernas por haber sido durante épocas de crisis política (guerras, invasiones, entre otros), resguardo de reliquias, o por la aparición de imágenes (op. cit.: 279).

\section{Estudios etnográficos en México}

En nuestro país son varios los santuarios que han sido abordados desde diferentes enfoques; incluso hay trabajos donde se muestra que la práctica de peregrinar es muy antigua entre los pueblos mesoamericanos. Barba de Piña Chan (1998) ha señalado la existencia de diferentes peregrinaciones en el Altiplano Central antes de la llegada de los españoles, mismas que fueron recogidas por algunos cronistas, cuyas descripciones dan cuenta de la existencia y reconocimiento de varios puntos o sitios que comprendían éstas, así como los sacrificios (se padecía hambre, frío, fatiga, etcétera) y rituales que se realizaban en honor a los dioses, características que aún se conservan en las peregrinaciones actuales. Al parecer, esta práctica proliferó durante el período clásico, época en la cual se hicieron amplios caminos que comunicaban con centros de la devoción mesoamericana; se cita el caso de Chichén Itzá (op. cit.: 18).

Uno de los santuarios más conocidos de México y más visitados a nivel mundial es el de la basílica de la Virgen de Guadalupe, en la capital del país. Varios investigadores sobre la temática peregrinación-santuario lo han estudiado, como Cámara y Reyes (1975). Entre sus planteamientos más importantes, estos autores destacan el concebir a la peregrinación como una fuerza integradora o de cohesión. Consideran que los santuarios, por ubicarse en su mayoría en espacios urbanos, atraen a grupos heterogéneos, especialmente "populares", que al peregrinar y llegar al santuario entran en contacto con ámbitos modernos y se alejan de sus "contextos mágicos y socio-religiosos (pagano-católico)" (op. cit.: 13). Es así que, para estos autores, el binomio peregrinación-santuario tiende a homogenizar a la sociedad nacional.

En torno al mismo santuario está el estudio de Carlos Garma (1994), que trata la peregrinación anual del pueblo de Iztapalapa hasta el Tepeyac. Entre los aspectos que destaca se encuentra el de la "inversión" del poder masculino en 
la peregrinación, específicamente de los mayordomos, que adoptan una posición ritual de subordinación frente a mujeres jóvenes, quienes desempeñan un papel más importante al cargar las imágenes de la Virgen. Esto es significativo sobre todo porque el papel protagónico de las mujeres en rituales es poco frecuente en zonas indígenas. Para el autor, esta inversión puede explicarse por los "atributos simbólicos que se tienen del culto mariano": castidad y pureza, que se exigen a las mujeres "cargadoras", pero también al carácter liminoide de la peregrinación señalado por Turner y que "fomenta la inversión simbólica de las diferencias cotidianas" (op. cit.: 75).

Uno de los primeros trabajos en torno al tema es el de Miguel Othón de Mendizábal (1946), quien estudió el santuario del Señor de Chalma, en el estado de México. Lo abordó de forma descriptiva y general, destacando el origen prehispánico del santuario y la forma en que la Iglesia católica le dio continuidad como centro devocional cristiano al suscitarse el "milagro" del Cristo. Describe las peregrinaciones de los indígenas y las dificultades por las que pasan, así como la forma en que rinden culto al Cristo o Señor de Chalma.

Entre los estudios que más han aportado al tema en cuestión se encuentra el de Gilberto Giménez (1978), quien aborda el proceso de peregrinación a Chalma abarcando tanto el santuario como a los peregrinos, porque considera que son aspectos privilegiados para observar y analizar las formas de expresión de la religión popular. ${ }^{1}$ En la peregrinación que estudió se da la circulación de santos patronos. El hecho de que los santos se visiten, y acudan al santuario de Chalma, ocurre porque es su "obligación", semejante a una relación de compadrazgo. Las alianzas entre los santos significan la protección y posibilidad de supervivencia de la comunidad. Para Giménez, el verdadero "sujeto" de la peregrinación es el pueblo entero, simbolizado por las imágenes de sus santos patronos, ya que éstos "funcionan como símbolos o emblemas de la comunidad", por eso cuando el pueblo se desplaza, necesariamente deben llevar los símbolos de su identidad, lo cual explica la circulación de imágenes en la religión popular (op. cit.: 103-105 y 147).

Un aspecto que el autor resalta de la peregrinación es la solidaridad, tanto la que se establece entre los peregrinos como la que se expresa durante el camino entre los pueblos vecinos. Afirma que la religión popular funciona "hacia adentro", porque las imágenes son símbolos de identidad; en este sentido, representaría una ideología de integración social, pero también una fuerza impugnadora "hacia afuera", al negar la cultura religiosa dominante, y porque continuamente resiste a la religión oficial y a todo aquello que la amenaza "desde afuera" (op. cit.: 234-248).

\footnotetext{
${ }^{1}$ Giménez define la religión popular rural como "el conjunto de todas las prácticas simbólicas consideradas como religiosas por los campesinos pueblerinos tradicionales, dentro del conjunto de sus prácticas y de sus relaciones sociales" (op. cit.: 20).
} 
El santuario de Chalma también ha sido estudiado por Shadow y Rodríguez (1994), quienes resaltaron más la peregrinación que el punto de llegada o santuario, considerando que éste ha sido poco apreciado dentro del proceso. Analizan de manera crítica la propuesta de los Turner (op. cit.), especialmente los conceptos de liminoide y communitas, y por ende de "antiestructura", que ha llevado a polarizar el fenómeno de la peregrinación como transformadora o integradora, por lo que prefieren retomar la idea de Giménez con respecto a que la peregrinación tiene un carácter dual y contradictorio: afirmando su función integradora "hacia dentro" pero al mismo tiempo su fuerza impugnadora "hacia fuera" (op. cit.: 114).

Los autores hacen una interpretación de los símbolos, ritos y ceremonias más importantes de la peregrinación, pues mediante ellos se marca simbólicamente la transición del espacio mundano al sagrado o divino; así estos actos sirven como mecanismos transformadores y trasladan a los participantes al espacio de lo liminoide, donde puede darse algo extraordinario que en lo cotidiano no es posible, como un proceso de inversión: lugares sin importancia, la adquieren y se cambian las estructuras normales, por eso los peregrinos se expresan y actúan en forma independiente de la Iglesia. Además, señalan que como los peregrinos son personas desamparadas en búsqueda de salud, bienestar, liberarse de sus deudas, etcétera, al peregrinar pretenden escapar de las relaciones que los oprimen cotidianamente, lo cual es visto por los autores como una forma de resistencia que nutre la tradición de impugnación y de oposición contra un sistema considerado injusto (op. cit.: 118-125).

El trabajo de Bravo Marente (1994) aporta una interpretación diferente de las anteriores. Retoma de los Turner la idea de que las peregrinaciones forman un campo "en el cual se hallan marcados numerosos puntos de referencia que permiten la relación con lo sagrado y señala los límites materiales de su territorio" (op. cit.: 47). En este sentido, el autor ve en el peregrinar una estrategia de los grupos indígenas para conservar y recuperar un territorio, pues constituye una forma ritualizada de trazar un espacio. Resalta que para la población indígena el peregrinar, además de su carácter religioso, es una manera de legitimar su espacio de reproducción social y cultural. El territorio, entre los indígenas, no sólo es un elemento de reproducción biológica, sino "la fuente de su cosmovisión, el sustento de sus creencias y costumbres, y el asiento de su origen y pasado común, de su identidad" (op. cit.: 41). Presenta datos de varias peregrinaciones de grupos indígenas de la sierra norte de Puebla y muestra cómo, mediante el peregrinaje, estos grupos traspasan las líneas estatales que dividieron su territorio anterior y que en términos culturales seguían manteniendo cierta unidad, y también cómo se recupera o reapropia un espacio sagrado.

Otro estudio que ha permitido entender mejor el binomio peregrinación-santuario es el de Alicia Barabas (1995) en torno al aparicionismo, fenómeno que considera de la religiosidad popular, el cual "se configura a partir de las visiones que tienen algunas personas de seres pertenecientes a una realidad no or- 
dinaria". Suele presentarse a individuos o grupos en crisis "a quienes hacen destinatarios de su cuidado y mensajes, a cambio de veneración y esperanzas" (op. cit.: 29). Así, el suceso y los milagros de la imagen aparecida propician la creación de nuevo culto y atraen peregrinos. Plantea que este fenómeno incide en la "construcción colectiva de las nociones de identidad y territorialidad", pues la irrupción de lo sagrado hace del lugar algo diferente, especial; la imagen escoge al pueblo que ha de cuidarla, pero también el espacio donde se le rendirá culto; de alguna manera delimita su territorio, hecho que provoca que el pueblo a quien se le presentó confirme su calidad de elegido, y esto contribuye a la creación o recreación de identidades colectivas. Apunta que en muchas apariciones, especialmente las vinculadas con grupos indígenas, se manifestaron en sitios de culto prehispánico como cuevas, cerros, pozos, etcétera, lugares considerados sagrados (op. cit.: 30-39).

\section{Aportaciones etnográficas sobre la temática en la península de Yucatán}

En la península de Yucatán existen registrados más de 20 santuarios (oficiales y no oficiales) (Quintal et al., 2003: 329) (mapa 1). Uno de los primeros trabajos en la península en torno a la temática es el de Fernández y Negroe (1997) sobre la Virgen de Tetiz y su peregrinación al pueblo de Hunucmá, sitio al que llega

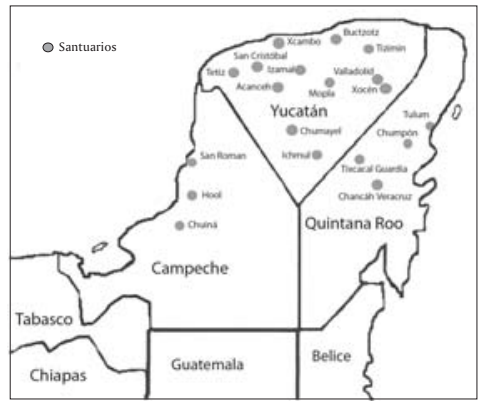

Mapa 1. Santuarios de La Península de Yucatán Dibujo de Agustín Medina 
anualmente para encabezar como patrona la fiesta. El fenómeno ocurre al poniente del estado de Yucatán. Los autores estudian la tríada santuario-peregrinación / procesión-fiesta patronal porque consideran que en conjunto contribuyen a reforzar manifestaciones y relaciones sociales (op. cit.: 112). Parten de las ideas de Diez Taboada (op. cit.) y de Christian (citado por Diez Taboada) para analizar el proceso por el que un lugar pasa a ser un santuario, reconociendo una relación estrecha entre lugar e imagen, lo que convierte las apariciones y milagros en aspectos centrales para la creación de santuarios, pues la trayectoria milagrera del lugar y la imagen provocan las peregrinaciones (Fernández y Negroe, op. cit:: 106-107).

Dichos autores ven al santuario como un espacio delimitado por la presencia de la imagen, que se relaciona con el espacio en la medida que al encontrarse en él lo transforma. La prioridad dada a las imágenes en la constitución de los santuarios, les sirve para explicar en ciertos casos la movilidad de las mismas, tal y como sucede con la Virgen de Tetiz, que los lleva a plantear dos tipos de santuarios: el localizado y el ampliado. Se refieren al primero como el lugar que guarda la imagen por más tiempo durante el año y cuyos habitantes son responsables de cuidarla y tienen el control de la misma. El santuario ampliado sería el lugar donde la imagen se queda momentáneamente después de peregrinar; su presencia convierte el lugar en santuario y en centro de peregrinación, y sus habitantes asumen la responsabilidad de custodiarla durante el tiempo que permanece en el lugar (op. cit.: 107-108). En el caso estudiado, Tetiz es el santuario localizado y Hunucmá el ampliado.

Vale añadir que Fernández y Negroe coinciden con Giménez (op. cit.) respecto a que las peregrinaciones como práctica de la religión popular "construyen y reafirman identidades sociales", situación a la que contribuye también la fiesta patronal. En la tríada que abordan encontraron que se manifiestan varias identidades sociales, especialmente entre algunos grupos participantes (los cargadores y los gremios) que expresan diferentes identidades: religiosa, local y nacional, ocupacional y hasta una identidad étnica maya mestiza presente en el vestido, el baile, la lengua, la comida, etcétera (op. cit.: 121-124).

Otro trabajo en Yucatán que aborda tanto el fenómeno de la peregrinación como el santuario, es el realizado por Ella Fanny Quintal (2000) sobre el sitio arqueológico de Xcambó, como santuario de la Virgen de la Inmaculada Concepción. El sitio se ubica en el municipio de Dzemul, al noroeste de Mérida. Personas de los alrededores peregrinan hasta el sitio arqueológico con algunas imágenes de la Virgen para rendirle culto en el lugar donde se apareció, motivo por el cual se le conoce más como la Virgen de Xcambó. Con base en las ideas de Barabas (op. cit.) sobre el aparicionismo, la autora explica cómo la aparición de la Virgen (misma que todavía se sigue presentando, pero sólo ante los que tienen fe), sacraliza el lugar y legitima el uso del territorio para rendirle culto a la "verdadera dueña" del mismo, siendo hoy de propiedad privada y del Estado (Quintal, op. cit.: 292). 
Como varios de los anteriores autores, Quintal utiliza el enfoque teórico de los Turner para analizar el carácter liminoide de la peregrinación, fenómeno mediante el cual los peregrinos se alejan de las normas sociales, valores y relaciones que cotidianamente rigen sus vidas, para dar paso al compañerismo, afectividad, sacrificio (situaciones de liminalidad y communitas). Los participantes permanecen una noche en el santuario de Xcambó, compartiendo trabajos y peligros que implican estar en el monte, pero también las comidas y las pláticas. En el sitio sagrado conviven de manera respetuosa el jmen o sacerdote maya con el sacerdote de la iglesia, igual que la Virgen y los sagrados vientos, a quienes por igual se les reza en lengua maya y se les ofrenda. Así muestra que "el lugar y el tiempo de peregrinar son ocasión para la creación cultural" y sugiere que la celebración puede verse desde la perspectiva utópica en tanto que se rompe con lo cotidiano y se entra "a lo que propiamente debería ser" (Quintal, op. cit.: 291, 300-304).

Contamos también con un trabajo de Quiñones (2002) sobre la Virgen de Mopilá, Yucatán, imagen que cada año llevan en peregrinación de la iglesia del pueblo de Yaxcabá hasta el antiguo poblado de Mopilá, hoy deshabitado. El artículo pretende mostrar cómo la población al llevar en peregrinación a la Virgen que fue la patrona de Mopilá y tierra de sus antepasados, convierte este sitio en un santuario o territorio sagrado y les permite conservar un espacio que alimenta su identidad colectiva. Ambos fenómenos son analizados con base en las ideas de Bravo (op. cit) y Giménez (1999) sobre el territorio. Por un lado la peregrinación es una estrategia del pueblo para preservar un espacio que consideran suyo en tanto rememora su pasado, y por otro lado el santuario, meta de la peregrinación y territorio sagrado, es visto como un espacio de inscripción de un pasado histórico y como soporte de identidades colectivas, o lo que Giménez (op. cit.) denomina geosímbolo, donde hace referencia a la relación entre cultura y territorio, en tanto que este último constituye un espacio donde se inscribe la cultura, pero también guarda relación con procesos identitarios (Quiñones, op cit.: 160). En el trabajo se muestra la participación del pueblo y las formas de organización propias que ha generado para realizar la peregrinación hasta el lugar donde vivieron sus antepasados, que consideran propio, y donde manifiestan su cultura (véase foto).

Entre las publicaciones más recientes en torno al tema, se encuentran las relativas a dos santuarios del estado de Campeche, Chuiná y Hool. El primero, de Medina y Rejón (2002), muestra cómo el peregrinar hasta el santuario de los devotos de la Virgen de Chuiná constituye un mecanismo de marcaje de un territorio regional definido históricamente y del que se apropian simbólicamente. Las peregrinaciones inician hacia los primeros años del siglo xx sobre "el espacio que un siglo antes se dedicaba a la producción cañera", por lo cual los peregrinos, la mayoría población maya, "recorren sin saberlo los antiguos territorios" donde trabajaron y habitaron sus antepasados (op. cit.: 483-485 y 489). El análisis se realiza desde la perspectiva de la territorialidad de Bravo (op. cit.). 


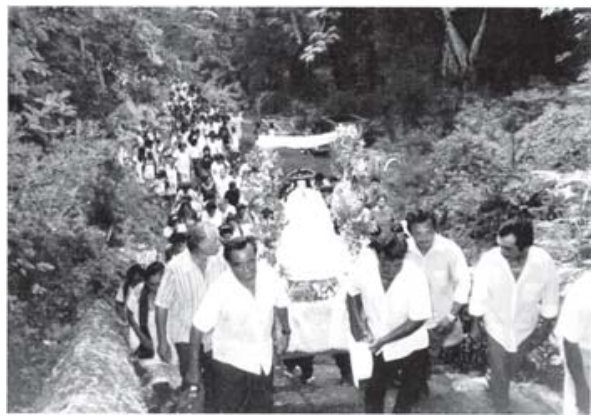

LLEGADA DE PEREGRINOS A MOPILÁ

Foto: Teresa Quiñones

También plantean que la región devocional del santuario está definida por el área de donde provienen los peregrinos que llegan a él, procedentes de localidades de los tres estados de la península de Yucatán y Tabasco, lo cual hace que, por su radio de influencia, el santuario de Chuiná sea regional.

Desde el fenómeno del aparicionismo de Barabas, las autoras abordan el santuario donde se apareció la Virgen Dolorosa y todavía lo hace, en los días previos y durante la Semana Santa, especialmente en la laguna, el pozo y el cerro, lugares sagrados por la "presencia" de la imagen, y que junto con la capilla, son los puntos que todo peregrino debe recorrer. Consideran que la aparición de la Virgen sacraliza el lugar y sirve para sustentar "la apropiación" del territorio, pues todo parece indicar que el asentamiento de Chuiná se origina a partir de las peregrinaciones, siendo actualmente este fenómeno la principal fuente de ingresos de sus habitantes (op. cit.: 484-488).

Hool es otro santuario campechano investigado por Quiñones y Quintal (2002). Analizan las peregrinaciones que se crean con el culto, especialmente las situaciones de liminalidad y communitas, según la teoría turneriana, que los peregrinos de la Virgen de Hool experimentan durante el viaje y en el santuario, donde se dan muestras de compañerismo, conciliación, etcétera.

También con base en las ideas del aparicionismo de Barabas (op. cit.) analizan el sitio sagrado. Es el santuario de la Virgen de la Candelaria, mejor conocida como la Virgen de Hool por haberse aparecido en una aguada del lugar. La 
imagen dio nombre al pueblo, en él se apareció, y pese a que fue sacada varias veces, "regresó", y ya en el pueblo, "señaló" el cerro como el lugar exacto donde quería se le venerase. La aparición de la imagen y las señales que emitió sirven a los lugareños para justificar que es su pueblo, Hool, el elegido como territorio para su culto, y ellos, los elegidos para cuidarla. Así también, esta imagen es custodiada por un reptil, un cocodrilo, pues esta Virgen, como la de Xcambó, Chuiná y otras aparecidas en la península de Yucatán, está relacionada con elementos de la cultura maya: agua-caverna-luna, cerro y animales, como culebras, cocodrilos, etcétera (Quiñones, op. cit.: 495-500).

Bartolomé y Barabas plantearon que entre los mayas de Quintana Roo, la práctica religiosa de la peregrinación, que denominaron "sistema de procesiones" (1981: 56) reemplazaba al sistema de guardia, organización teocrático-militar propia de este grupo, y servía para fortalecer sus lazos, especialmente entre pueblos con sistema de guardia y pueblos sin guardia. Se refieren al ritual que se realiza en torno a la imagen de Juan de la Cruz del pueblo de Kopchén. En esta peregrinación participa la imagen "representada" por la cruz que posee el santo, acompañada por la gente de los pueblos que recorre, donde recibe ofrendas que servirán para la fiesta que se lleva a cabo en su pueblo; misma que marca el fin de la peregrinación (id.). Cabe señalar que los autores no hicieron un estudio específico sobre el fenómeno, pero la hipótesis que plantean resulta interesante y contribuye a entender las relaciones interétnicas entre los mayas de esta región.

Sobre los mayas de Quintana Roo existe asimismo una ponencia de Quiñones (2003) que de manera general describe las peregrinaciones que éstos realizan cada determinado tiempo a los diferentes santuarios que reconocen en su territorio. Plantea que los mayas del centro quintanarroense y los del oriente de Yucatán marcan un territorio que les fue fragmentado al establecerse la división política-geográfica de cada estado, siendo la peregrinación, como señala Bravo (op. cit.), una estrategia para marcar su territorio, que aún persiste en su memoria colectiva y que ahora trazan de manera ritual para conservarlo, al menos a nivel simbólico (Quiñones, op. cit.: 11-12) (mapa 2).

Las peregrinaciones y los santuarios fueron también, entre otros, tema de investigación del proyecto "Etnografía de los mayas de la península de Yucatán", realizado durante el año 2001 por el Centro INAH, Yucatán. ${ }^{2}$ Las aportaciones de este proyecto a nivel peninsular rebasaron la perspectiva local de los estudios en torno a las peregrinaciones y santuarios realizados hasta entonces, y que ya mencionamos (Fernández y Negroe, op. cit., y Quintal, 2000). En los trabajos derivados del mismo, sobre los santuarios de Chuiná y Hool, en Campeche, en Yucatán y, de la zona maya macehual, en Quintana Roo, se observa que

\footnotetext{
${ }^{2}$ El resultado final fue publicado en el ensayo "U lu'umil maaya wiinikob: La tierra de los mayas", coordinado por Ella Fanny Quintal Avilés, en Diálogos con el territorio, Alicia Barabas (ed.), 2003.
} 


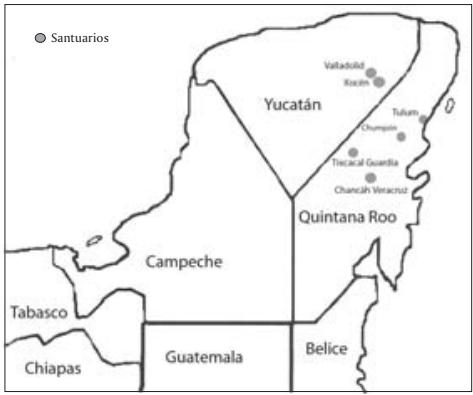

Mapa 2. Zona maya maceHUÁ.

la temática tiende a ser analizada desde la perspectiva de la territorialidad, fundamentalmente porque ese fue el tema central del proyecto mencionado.

En el proyecto se abordaron 19 santuarios, mismos que fueron clasificados por su origen histórico.

a) santuarios prehispánicos, aquellos que desde antes de la llegada de los españoles fueron espacios sagrados como plataformas, edificios, cenotes, cuevas, aguadas, cerros o lagunas, entre otros. En efecto, las fuentes históricas nos mencionan lugares sagrados como Izamal, Tizimín, Chichén Itzá, Tulum y Cozumel, algunos de los cuales son todavía santuarios en la devoción religiosa.

b) Santuarios coloniales. Surgieron bajo la dominación española promovidos por los religiosos durante la evangelización, y fueron aceptados por la población maya, como el culto a los cristos negros (Cristo negro de Campeche y Cristo negro de Sitilpech en Yucatán), que por sus obras milagrosas se arraigaron en la religiosidad popular maya, o el santuario a la Virgen de Hool en Campeche, cuya aparición se remonta a las primeras décadas de la invasión española.

c) Santuarios modernos; aquellos que surgieron después de la independencia de México y están estrechamente relacionados con milagros aparicionistas y con determinados momentos históricos, como la llamada Guerra de Castas (los santuarios de la zona maya de Quintana Roo) y la Revolución 
mexicana, expresada localmente en la época conocida como "alvaradista" — por el período de gobierno del General Salvador Alvarado en Yucatán (1915-1917) — y que se manifestó en las "reapariciones" de imágenes que fueron escondidas en cuevas, pozos y otros lugares considerados sagrados en la cosmogonía maya, por la "persecución" del Estado (Quintal et al., 2003: 331-334) (cuadro 1).

Cuadro 1. Tipología de santuarios según su origen

\begin{tabular}{|l|l|l|l|}
\hline \multicolumn{1}{|c|}{ Prehispánicos } & \multicolumn{1}{|c|}{ Coloniales } & \multicolumn{1}{|c|}{ Modernos } & \multicolumn{1}{c|}{ Móviles } \\
\hline $\begin{array}{l}\text { Inmaculada } \\
\text { Concepción, } \\
\text { Izamal, Yucatán }\end{array}$ & $\begin{array}{l}\text { Santo Cristo } \\
\text { de San Román, } \\
\text { Campeche }\end{array}$ & $\begin{array}{l}\text { Chuiná, } \\
\text { Campeche }\end{array}$ & $\begin{array}{l}\text { Gran poder } \\
\text { de Dios, } \\
\text { Conkal, Yucatán }\end{array}$ \\
\hline $\begin{array}{l}\text { Tres Reyes Magos } \\
\text { Tizimín, Yucatán }\end{array}$ & $\begin{array}{l}\text { Santo Cristo } \\
\text { de Sitilpech, } \\
\text { Izamal, Yucatán }\end{array}$ & $\begin{array}{l}\text { Zona maya } \\
\text { de Quintana Roo } \\
\text { (Tixcacal Guardia, } \\
\text { Chumpón, Tulum, } \\
\text { Chancáh Veracruz) }\end{array}$ & $\begin{array}{l}\text { Cruz de Popox, } \\
\text { Hocabá, Yucatán }\end{array}$ \\
\hline Tabi, Sotuta & $\begin{array}{l}\text { La pobre } \\
\text { de Dios, } \\
\text { Tetiz, Yucatán }\end{array}$ & $\begin{array}{l}\text { Yobaín, } \\
\text { Yucatán }\end{array}$ & $\begin{array}{l}\text { La Virgen } \\
\text { de Chuiná, } \\
\text { Mérida, Yucatán } \\
\text { Yucatán }\end{array}$ \\
\hline & $\begin{array}{l}\text { Virgen de Hool, } \\
\text { Campeche }\end{array}$ & $\begin{array}{l}\text { La Virgen } \\
\text { de Lamá, } \\
\text { Umán, Yucatán }\end{array}$ \\
\hline
\end{tabular}

Elaboración de las autoras

Una variante de la península, y que se destaca en el proyecto, es el movimiento de imágenes de un pueblo a otro, que se optó por denominar como "santuarios móviles". Se trata de imágenes "propiedad" de alguna familia que viajan a diferentes lugares donde se les rinde culto. El fenómeno se manifiesta como una religiosidad autónoma de las autoridades eclesiásticas, y se interpreta como un culto clandestino ante la persecución religiosa que se diera en la colonia o en el período "alvaradista". Ejemplos de esta variante serían los casos de las Cruces de Popox de Hocabá y el Gran Poder de Dios de Conkal en Yucatán.

Otra variante de esta movilidad de imágenes se da en el norte del mismo estado, con el recorrido de la Virgen "viajera" de Buctzotz, patrona de esta co- 
munidad que "peregrina" a diferentes pueblos de esta región durante un año. El recorrido de estas imágenes reconstruye regiones con una significación histórica, v. g. un territorio prehispánico o colonial (op. cit.: 332-334).

Con base en los resultados de la investigación se observó que los santuarios de la península dan "testimonio de la antigua visión maya del cosmos. En los mitos de origen, en las creencias y en el culto aparecen cuevas, cenotes, lagunas, así como cocodrilos y serpientes que devoran a los incrédulos o custodian a la imagen" (op. cit.: 335).

El proyecto distingue dos tipos de peregrinaciones: la primera, cuando los fieles recorren el territorio en la forma tradicional del comportamiento romero, y la segunda, cuando las imágenes y sus fieles peregrinan; esta forma se da cuando una comunidad se traslada a otra para buscar a la imagen y llevarla para venerarla como patrona temporal, convirtiéndose así la comunidad receptora en "santuario temporal". Éstos son los casos de la Virgen de Tetiz, llevada a Hunucmá, y del Cristo de Sitilpech, trasladado a Izamal, ambos en el estado de Yucatán. También reconocieron las dos formas básicas en que los peregrinos realizan su recorrido: a) grupos familiares, de amigos o de la misma edad o género y, b) grupos corporados que pueden unirse por medio de una antigua organización tradicional conocida en Yucatán como gremios o la de los antorchistas (corredores a pie o en bicicleta, que llevan una antorcha encendida), costumbre muy arraigada en los pueblos mayas de la península desde hace más de 50 años (op. cit.: 337-342).

Otra aportación a la etnografía de las peregrinaciones-santuarios está vinculada a la propuesta de González Alcantud (1988) sobre las tensiones que surgen entre dos comunidades devotas del mismo santo, que es propiedad de una comunidad de menor rango y jerarquía. Esa circunstancia genera disputas entre dos poblaciones porque finalmente significa la subordinación de la de mayor jerarquía con relación a la menor. Tales son los casos, entre otros, de Tetiz y Hunucmá, Chumayel y Teabo, Citilcum y Tekantó, todos ellos en el estado de Yucatán. Se interpreta como una necesidad del clero durante la evangelización para atraer al culto a los mayas, mediante la promoción del poder curativo o milagroso de ciertas imágenes ubicadas en sus comunidades, pero que los habitantes de poblaciones de mayor rango necesitaban para sobrevivir (Quintal, op. cit.: $342-343)$.

\section{Comentario final}

Después de "peregrinar" por los santuarios de la península de Yucatán a través de los diferentes estudios que se han realizado en los tres estados que componen la región, consideramos que estos trabajos sobre la temática peregrinaciónsantuario han tendido a analizar de manera conjunta ambos fenómenos. Esto ha permitido un conocimiento general sobre estos aspectos de la religión po- 
pular, especialmente entre los mayas peninsulares, de tal suerte que no sólo se cuenta con una tipología de santuarios y una tipología de peregrinaciones, sino sobre todo con diversas interpretaciones que dan fe de la presencia y vigencia de la cosmovisión maya y nos permiten entender las formas o mecanismos que tiene la etnia maya para crear y recrear su cultura, fortalecer su identidad y "legitimar" un territorio.

\section{BIBLIOGRAFÍA}

Barba de Piña Chan, Beatriz

1998 "Peregrinaciones prehispánicas del Altiplano mesoamericano", en Caminos terrestres al cielo, pp. 17-48, B. Barba de Piña Chan (coord.). México: Instituto Nacional de Antropología e Historia.

Barabas, Alicia

1995 "El aparicionismo en América Latina: religión, territorio e identidad", en La identidad: imaginación, recuerdo y olvidos, pp. 29-40, A. Pérez Castro (ed. y coord.). México: UNAM, Instituto de Investigaciones Antropológicas.

Bartolomé, Miguel y Alicia Barabas

1981 La resistencia maya: relaciones interétnicas en el oriente de la península de Yucatán, $2^{\text {a }}$. ed. México: Instituto Nacional de Antropología e Historia, (Colección Científica, 53).

Bravo Marente, Carlos

1994 "Territorio y espacio sagrado", en Las peregrinaciones religiosas: una aproximación, pp. 39-50, C. Garma y R. Shadow (coords.). México: UAM Itzapalapa.

Cámara Barbachano, Fernando y Teófilo Reyes Couturier

1975 "Los santuarios y las peregrinaciones", Anales (IV): 5-22, México: Instituto Nacional de Antropología e Historia.

Díez Taboada, Juan María

1989 "Significación de los santuarios", en La religiosidad popular. Hermandades, romerías y santuarios, III, pp. 268-281, C. Álvarez Santaló, M. Buxó i Rey y S. Rodríguez Becerra (coords.). Barcelona: Ánthropos.

Fernández, Francisco y Genny Negroe S.

1997 "Caminando y paseando con la Virgen. Prácticas de la religión popular e identidades sociales en el noroeste de Yucatán", en Identidades sociales en Yucatán, pp. 99-131, M. C. Lara (comp.). Mérida: Universidad Autónoma de Yucatán, Facultad de Ciencias Antropológicas.

Garma, Carlos

1994 "La peregrinación de Iztapalapa al Tepeyac", en Las peregrinaciones religiosas: una aproximación, pp. 65-80, C. Garma y R. Shadow (coords.). México: UAM Iztapalapa. 
Giménez, Gilberto

1978 Cultura popular y religión en el Anáhuac. México: Centro de Estudios Ecuménicos.

1999 "Territorio, cultura e identidades. La región sociocultural", Estudios sobre las Culturas Contemporáneas, 9: 1-33. México: Univesidad de Colima.

González Alcantud, José Antonio

1988 "Territorio y religión popular en Andalucía oriental", en La religiosidad popular: hermandades, romerías y santuarios, 1, pp. 197-214, C. Álvarez Santaló, M. Buxó i Rey y S. Rodríguez Becerra (coords.). Barcelona: Ánthropos.

Medina, Martha y Lourdes Rejón

2002 "El santuario de Chuiná, Campeche. Centro de una región histórica y cultural", Los Investigadores de la Cultura Maya, 10 (II): 482-493. México: Universidad Autónoma de Campeche.

Othón de Mendizabal, Miguel

1946 "El santuario de Chalma”, en Obras Completas, II: 509-520. México: Talleres Gráficos de la Nación.

Prat i Carós, Joan

1989 "Los santuarios marianos en Cataluña: una aproximación desde la etnografia", en La religiosidad popular: hermandades, romerías y santuarios, III, pp. 211-252, C. Álvarez Santaló, M. Buxó i Rey y S. Rodríguez Becerra (coords.). Barcelona: Ánthropos.

Quintal Avilés, Ella Fanny

2000 "Vírgenes e ídolos: La religión en las manos del pueblo", Mesoamérica, 39: 287-304. South Woodstock, EUA: Plumsock Mesoamerican Studies.

et al.

2003 "U lu'umil maaya wíniko'ob: La tierra de los mayas", en Diálogos con el territorio. Simbolizaciones sobre el espacio en las culturas indígenas de México, pp. 273-360, A. Barabas (ed.). México: Instituto Nacional de Antropología e Historia (Colección Etnografía de los Pueblos Indígenas de México, l).

Quiñones Vega, Teresa

2002 "Peregrinar con la Virgen para volver al propio territorio", Temas Antropológicos, 24 (2): 144-165. Mérida: Universidad Autónoma de Yucatán, Facultad de Ciencias Antropológicas.

2003 "La peregrinación, una práctica religiosa de los mayas macehuales para conservar su territorio", ponencia presentada en la Expo-Maya, en Felipe CarriIlo Puerto, Quintana Roo.

y Ella Fanny Quintal Avilés

2002 "Hool, territorio sagrado del pueblo campechano", Los Investigadores de la 
Cultura Maya, 10, tomo II, pp. 454-503. Campeche: Universidad Autónoma de Campeche.

Saravia, Javier

2000 La religiosidad popular, extranjera en su propia tierra. México: Obra Nacional de la Buena Prensa.

Shadow, Robert y María Rodríguez Shadow

1994 "La peregrinación religiosa en América Latina: enfoques y perspectivas", en Las peregrinaciones religiosas: una aproximación, pp. 15-38, C. Garma y R. Shadow (coords.). México: UAM Iztapalapa.

Turner, Victor, y Edith Turner

1978 Image and Pilgrimages in Christian Culture. Nueva York: Columbia University.

Turner, Victor

1988 El proceso ritual. Estructura y antiestructura. Madrid: Taurus. 